\title{
Comparative Water Efficiency Analysis of Sole and Multiple Cropping Systems under Tunnel Farming in Punjab-Pakistan
}

\author{
Hina Fatima1, Lal K. Almas ${ }^{2 *}$, Sehrish Haroon ${ }^{3}$ \\ ${ }^{1}$ Department of Finance and Economics, Mohammad Ali Jinnah University, Karachi, Pakistan \\ ${ }^{2}$ Paul Engler College of Agriculture and Natural Sciences, West Texas A \& M University, Canyon, TX, USA \\ ${ }^{3}$ Department of Public Administration, Fatima Jinnah Women University, Rawalpindi, Pakistan \\ Email: Hina.fatima@jinnah.edu, *lalmas@wtamu.edu,Sehrishharoon@fjwu.edu.pk
}

How to cite this paper: Fatima, H., Almas, L.K. and Haroon, S. (2020) Comparative Water Efficiency Analysis of Sole and Multiple Cropping Systems under Tunnel Farming in Punjab-Pakistan. Journal of Water Resource and Protection, 12, 455-471. https://doi.org/10.4236/jwarp.2020.126027

Received: March 27, 2020

Accepted: June 2, 2020

Published: June 5, 2020

Copyright $\odot 2020$ by author(s) and Scientific Research Publishing Inc. This work is licensed under the Creative Commons Attribution International License (CC BY 4.0).

http://creativecommons.org/licenses/by/4.0/

\begin{abstract}
Water scarcity is the growing concern of present times, requiring its efficient utilization deemed as necessity. Rapidly growing population has significantly exerted pressure on its demand, in Pakistan. In order to fulfill it, all factors of production are required to be used in the possibly most efficient way. Good quality and quantity of water are the growing concerns of producers in $\mathrm{Pa}$ kistan and around the globe. The efficient water utilization is crucial to optimize the farm returns under the selected sole and multiple cropping systems. This study considered the water efficiency analysis of multiple and sole cropping systems, with the aim of finding out cropping patterns more efficient in terms of water utilization in Pakistan. In order to estimate the water efficiency analysis, the Data Envelopment Analysis (DEA) is run to find out the water efficient cropping systems among sole and multiple cropping systems. The Tobit analysis is also used to find out the factors affecting the water efficiency of selected farms in the study area. The results of the study report an inefficient water usage in terms of irrigation, the inefficient use of water instigates the wastage of one of the most important as well as scarce farm inputs especially water, in case of multiple cropping system. Around $51 \%$ and $13 \%$ of water inefficiency are present under multiple and sole cropping systems, respectively. Basin irrigation is the method for irrigation, used by the farmers of the study area approximating to be $95 \%-97 \%$. It is one of the most conventional and least efficient methods of irrigation. Only 2.67 and 4.67 percent of farms were using the Furrow irrigation method, which is way more efficient and steady as compared to Basin irrigation method, respectively. It appears as a requirement that the most efficient methods regarding water application in Pakistan should be recognized. Lack of management in
\end{abstract}


water application on both selected cropping systems resulted in over utilization of water and depletion of one of the fundamental natural resource. In order to overcome the inefficiency in water management, farmers' farming knowledge, adoption of new irrigation techniques, efficient application of inputs is needed.

\section{Keywords}

Water Efficiency, Irrigated Agriculture, Sole and Multiple Cropping, Tunnel Farming, Punjab-Pakistan, Data Envelopment Analysis (DEA), Tobit Analysis

\section{Introduction}

Of all the resources endowed upon human race, water is responsible for maintaining the survival of living beings. However, it is not given value commensurate with its significance. In context of agrarian economy like Pakistan, it is one of the essential ingredients for the growth of all kinds of agricultural produce. There is no denying to the fact that agricultural sector development can play a significant role in economic uplifting of developing countries [1].

Endowment of water resources is not uniform around the globe. Under the increased demand and changing climatic conditions, some parts of the world are facing water scarcity. The case of Pakistan is no different from other developing countries where agricultural sector is one of the largest sectors of the economy. The significance of agricultural produce is undeniable with regards to fulfilling basic needs of the population and providing raw materials to other sectors of the economy. This sector is contributing $18.9 \%$ to GDP and is providing employment to $42.3 \%$ of Pakistan's population [2]. Looking at the input factors for agricultural sector and comparative to all other sectors in an economy, agricultural sector, by far, is the major consumer of water. This sector cannot thrive without water as input factor. Water availability is considered to be of high importance as there is around $90 \%$ dependence of agricultural produce on irrigation [3].

According to Ashraf and Shiekh, 2017 [4] and Ashraf and Hassan [5] water consumption in Pakistan, if segregated by sector, shows that one percent is in domestic use, two percent is in industrial use whereas the remaining $97 \%$ is used by the agricultural sector. Out of the whole geographical area, the cultivable land in Pakistan is 29.6 million hectares (Mha) while canal-irrigated area is $13.6 \mathrm{Mha}$, generating $90 \%$ of agricultural produce from 17 Mha irrigated land [6] and [7]. In order to increase cultivable land, aridity of land could be reduced by $9.7 \%$, conditioned upon maintenance of water availability [8]. Moreover, rainfall, a natural water resource has declined in Pakistan further decreasing river flows. Resultantly, Pakistan is at the verge of facing severe water shortage making dry cycle in Pakistan visible. According to the current population growth of 4 million per year, every third person will be facing critical scarcity of water posing 
challenges to survival [9].

According to the World Development Report in 1995, Pakistan was amongst the countries having the highest freshwater availability per capita. Farm gate water availability in total accounts to 134 million-acre feet. However, years 1997-2002 witnessed drought with continued scarcity over the passage of time. Water shortage was $11 \%$ in 2004, and is predicted to go as high as $31 \%$ in 2025 .

The major source of irrigation in Pakistan is canals and is known as the world's second-best water irrigation system. The formation of irrigation system of sub-continent began in mid-nineteenth century. After the establishment of Pakistan, Indus Basin Irrigation System, having three major reservoirs is irrigating this land. The total length of irrigating canals is $56,073 \mathrm{~km}$ using both ground and surface water [10]. In the last three decades, ground water has become the most prominent source of irrigation. However, considering the low water conservation, water efficiency is quite low. In addition to that, lesser water storage facilities are visible in Pakistan, being evident from 13.20 MAF comparative to $2280 \mathrm{MAF}$ of China and $245 \mathrm{MAF}$ of India in the South-Asian region [9].

Irrigational activities take up as one of the largest usages of water within agricultural sector. The data depicts that the amount of water used by various irrigational means for a specific period of time has increased. Out of the most frequently used sources, canal tube wells had remained the biggest means of supplying water to crops, according to the time period taken in the study i.e. 2010-15, whereas, canal wells, wells and other methods are scarcely used irrigational methods. The case of canals with regards to irrigation, lie somewhere between highly used canal tube wells and rarely used canal wells. By observing this data set, on average canal tube wells turn out to be widely used for irrigational purposes in Pakistan. The extraction of underground water surpasses annual refilling causing the water table to considerably decline, making the option of groundwater irrigation economically less profitable [11]. According to Khan, 1997 [12], there is huge difference between annual surface water availability and actual amount consumed by farmers that are $146 \mathrm{MAF}$ and $31 \mathrm{MAF}$, respectively. Various factors are responsible for causing huge losses such as seepage, overflow, thin distorted, silt-loaded banks, vegetation, convoluted sections rodent holes etc. [13].

There are no limitations, as such, placed on usage of groundwater in Pakistan and empirical support is non-existent in case of measuring on-farm water efficiency. If water is used efficiently, then the saved amount may be allocated to other water demands that will not only benefit the productivity, correspondingly water sustainability will also be improved. Irrigated land size is in negative relation with water efficiency [14]. According to Jalota et al. 2006 [15] the readily available water at low and subsidized costs, have lowered the efficiency of using water.

There is a dire need to look for effective ways of increasing water productivity. Water productivity, a related term, is sometimes synonymous to water efficien- 
cy. It can be defined as "the amount of food produced per unit volume of water used" [16]. Water scarcity, requires its efficient utilization through increased rate of urbanization and industrialization, greater quantity of water is directed towards cities and industrial units, thereby exerting greater pressure on its demand [17]. Rapidly growing population has significantly increasing demand for crops production. Bringing ideas and solutions for efficiently using water is beneficial, nevertheless it should go to the length of revising or revisiting patterns of water utilization. Improvement in irrigation techniques can also play a significant role.

According to Aziz et al. 2018 [18], the water accessibility in Pakistan in 1950s was around $5000 \mathrm{~m}^{3}$ per annum. Pakistan Council of Research in Water Resources in 2018 also proclaimed that Pakistan will face the water shortages and clean water availability by the year 2025 [19]. Aziz et al. 2018 [18] stated that water availability in Pakistan this day and age is declined below $1000 \mathrm{~m}^{3}$. If the water availability is below $1000 \mathrm{~m}^{3}$, then according to international given threshold, that country is specified as water scarce country. One of the report of International Monetary Fund (IMF) reported Pakistan as water scarce country and ranked it third among the water scarce countries [20].

The current alarming situation gives rise to the need of technically looking into the matter. Most of the studies conducted on water efficiency analysis are on the data of sole-cropping systems. One of the major objectives of this study is to carry out the water efficiency analysis of sole and multiple cropping systems in the selected areas of Pakistan. The comparative analysis of both cropping systems aimed at pointing out the most efficient cropping systems in terms of water utilization in Pakistan. The focus of this study is to extend empirical support to the efficient use of water as an input factor in multi and sole cropping systems. The cross-sectional data had been collected from the selected areas of Faisalabad, Pakistan, where farmers have gone beyond the traditional method of sole cropping. Specifying various aspects of water usage and its elements need to be considered before calculating and applying it in real-life situation.

In the light of this concept, the emphasis is on the notion of cutting down on unnecessary water usages. To achieve profitable level of output, factors like seed varieties, improved agronomic practices, farm size and time of sowing matters however, this study will highlight the effect and importance of water use in selected cropping systems.

For fulfilling the objective of the study, Data Envelopment Analysis (DEA) is applied in order to study non-parametric variables. DEA will generate relative efficiency of each selected cropping system along with the optimum level of irrigation required to be achieved by each cropping system. For finding out the factors affecting the water efficiency of selected cropping systems, Tobit analysis is also used in the study.

\section{Materials and Methods}

To compare water use efficiency among sole and multiple cropping systems (e.g. 
bitter gourd-capsicum and sole capsicum systems), data were collected from farmers who are cultivating bitter gourd-capsicum and sole capsicum crops in tunnels, in Punjab Pakistan. Tunnel farming is mostly performed in Faisalabad division of Punjab. The total population of tunnel farmers is approximately $900^{1}$, geographically highly segregated from each other. Therefore, locating them was cumbersome as well as costly. Some of the tunnel farmers were also located in the market, for they were in search of coming in contact with market through middleman.

Collection of sample for bitter gourd-capsicum was done from various cities of Punjab including Faisalabad, Mureed Wala, Sumundri, Tandnianwala, Toba Tek Singh, Gojra, Kamalia, and Mammu-Kanjan, with 12, 4, 24, 26, 15, 17, 12 and 38 number of farms, respectively.

For analyzing sole-cropping system, sample of amounting 150 farms of capsicum crop are taken. The respective number of farms from each city was collected including Faisalabad (45), Sumundri (51), Tandnianwala (25), Toba Tek Singh (05) and Mammo kanjan (24).

The identification of negative gaps is helpful to the government authorities in formulating efficient policies and the farmers in following those policies for eradicating the deficiencies of new high-tech farming systems.

For analyzing water efficiency, the data envelopment analysis (DEA) is taken into account. It based on non-parametric type of models for measuring the technical efficiency of group using same production units. Farell, 1957 [21] is accredited with the pioneer work on technical efficiency grounded upon the amount of input and output factors. The pioneer work on the development of DEA was done by Charnes, Cooper, and Rhodes in 1978 [22] and operates at constant return to scale. Ever since it had been used by various organizations and industries including health care, finance, education, and transportation. Later Banker, Charnes and Cooper, 1984 [23] introduced the (BCC) model, which operates at variable returns to scale because markets are imperfect when it comes to reality. Charnes Cooper Rhodes (CCR) model and Banker Charnes Cooper (BCC) model are the basic DEA models, differentiated by enveloping surfaces and positions. These surfaces can take form of CRS and VRS according to the CCR and BCC models, respectively.

This study used the single-output/single-input for sole and multiple cropping systems water efficiency analysis by considering the one input water in inches per acre. Hence, the input vector comprises the application of water (inches) per acre and output vector retains the output of sole and multiple cropping systems per acre. The two-step methodology is carried out in this study. In the first step, data envelopment analysis (DEA) is used to model efficiencies as an explicit function of discretionary variables. In the second stage Tobit regression analysis is used to find out the factor affecting the efficiency of selected cropping system.

${ }^{1}$ This is the rough estimate according to the experts of ARRI. 


\subsection{Constant Returns to Scale (CRS) Model}

This model represents the increase in inputs proportionate to increase in outputs. Nevertheless, markets do not function in an ideal manner.

$$
\begin{array}{r}
\operatorname{Min}_{\theta, \lambda} \theta \\
\text { St } \\
-y_{i}+Y \lambda \geq 0, \\
\theta x_{i}-X \lambda \geq 0, \\
\lambda \geq 0,
\end{array}
$$

In reality, imperfect competition prevails along with financial scarcities and therefore, output does not correspond proportionately to input for instance, increasing amount of water to crops does not increase crop production. Input model coincides with the aim of the study about sustainability of water and land resources and not about maximizing production. The DEA deals well with the assumption of returns to scale. In the first model Equation (1), all farms function optimally at linear scale under constant returns to scale. Generally, the BCC model envelops greater amount of data and efficiency scores are larger than or equal to scores of CCR model. For better explanation to this effect DEA model for VRS was formulated [23].

\subsection{Input Oriented Variable Returns to Scale Model}

Researchers have estimated the models either by using input oriented return to scale model or output oriented return to scale model by using DEA. The aims of both input-oriented model and out-oriented model are different. The input model aims for minimizing inputs while the output remains unchanged whereas; output model is about maximization of output with input factors held the same. The present study opted the input oriented return to scale model, as the objective is to find out the impact of water on farm output. Hence, selected model given below is best suited for the data in hand.

$$
\begin{aligned}
& \operatorname{Min}{ }_{\theta, \lambda} \theta \\
& \text { St } \\
& -y_{i}+Y \lambda \geq 0 \text {, } \\
& x_{i}-X \lambda \geq 0 \text {, } \\
& N 1 / \lambda=1 \text {, } \\
& \lambda \geq 0,
\end{aligned}
$$

Equation (2) shows $X_{\mathrm{i}}$ as an input vector for the $\mathrm{i}_{\mathrm{th}}$ farm and $y_{i}$ as an output vector. For the selection of optimal weights, this study considered the Coelli et al 1998 [24] mathematical programming problem, for the solution of optimal weights. The equation is run $\mathrm{n}$ times to get efficiency scores of farms and some weights are selected for maximization of efficiency scores. Those farms efficiency scores turn out to be 1 , show the efficient farms, and successful in attaining the optimum level of farm output on available water resources. While score of less than 1 shows inefficient farms. 


\subsection{Tobit Model}

The Tobit regression is extensively used at the second stage of DEA for farm efficiency analysis for examining the consequence of farm specific factors on the water efficiency of selected cropping systems. These factors are generally considered beyond the control of farm mangers to some extent. The DEA analysis gives the efficiency score range between zero and one. Consequently, the distribution of dependent variable does not remain normal [25]. The ordinary least square (OLS) regression analysis is not very appropriate for double censored dependent variable as it violates one of the basic OLS regression assumptions of consistent and unbiased estimator of OLS. The Two-limit Tobit regression model in case of latent dependent variable more accurately regresses the efficiency scores on socio-economic and farm specific factors, as efficiency scores are double censored. Hence for unknown parameter estimation, Tobit model based on maximum likelihood technique, is more binding [26].

The present study will apply the Tobit model at the second stage analysis of DEA. The model is as follows:

$$
\begin{gathered}
E S_{i}=\sigma Z_{i}+\varepsilon_{i} \\
E s_{i}=\left\{\begin{array}{l}
1, \text { if } E s_{i}^{*} \geq 1 \\
E s_{i}^{*}, \text { if } 0 \prec E s_{i}^{*} \prec 1 \\
0, \text { if } E s_{i}^{*} \leq 0
\end{array}\right.
\end{gathered}
$$

where $E s_{i}$ is observable efficiency and $E s_{i}{ }^{*}$ is an index, latent variable or non-observable efficiency that is based on efficiency scores of selected farms " $i$ ". The observed $E s_{1}$ is distinct as one, if $E s_{i}^{*}$ is greater than zero and zero if $E s_{i^{*}}$ is less than or equal to zero. The $Z_{i}$ is a vector of farm specific factors that may have influence on the efficiency of multiple and sole cropping system farms.

\section{Results and Discussion}

Water efficiency is a geographically related concept for the reason of efficiency being related with environment, infrastructural facilities and management of respective farms. Irrigation system improvement can lead to higher level of output and productivity of water. Lack of water management may give incorrect demand figures to farmers resulting in over-irrigation and ultimately leaving the land unusable. Timely and appropriate availability of water and methods of irrigation are the main two factors that lead to improved quality and quantity of farm output.

The water required to produce vegetables is greater than that required for other crops, like wheat, cotton, etc. The timely availability of water is imperative for crop development stages. In study area, a farmer depends on canal and tube well sources of water for irrigation.

Basin irrigation method is the most conventional method of irrigation used in Pakistan. However, application efficiency of basin irrigation is very low. Berkhout, 1997 [27] attributed the low application efficiency of basin irrigation to in- 
filtration characteristics of soil, field undulations, intake discharge and runoff. Approximately 97.33 percent and 95.33 percent of farms applied the irrigation by using basin method for irrigation in capsicum-bitter gourd and sole capsicum cropping systems, respectively. In case of capsicum-bitter gourd and sole capsicum cropping systems, around 2.67 percent and 4.67 percent of farmers used the furrow method for farm irrigation, respectively. Surface irrigation techniques however, can be improved by developing crop specific field layouts. Efficient surface irrigation methods such as bed and furrow irrigation system help to save water. Kahlown et al. 1998 [13] compared the results of cotton and wheat sowing on flat basin with bed and furrow. They concluded that cotton yielded maximum water use efficiency for bed and furrow method of irrigation, whereas the flat basin method of irrigation had the lowest yield and the highest water consumption. Therefore, the water saved in bed and furrow irrigation can be used to increase the cropping intensity and also for leaching the salts in salt affected soils. Based on water use efficiency, the bed and furrow method is the most efficient surface water application method.

On the other hand, it is need of the hour that farm sector of Pakistan transforms the obsolete method of irrigation and lend a hand, with the new available technologies of farm irrigation. One of the emerging methods for farm irrigation is drip irrigation which is highly suitable for tunnel farming. Drip-irrigated fields produced $22 \%$ higher yield and $26 \%$ higher production rates with less cost than fields irrigated by other methods [28].

Table 1 also reported that in study area, the number of irrigations in bitter gourd-capsicum and sole capsicum cropping systems. Irrigation is one of most important factors throughout development stages of the crop. The number of irrigation required for bitter gourd-capsicum and sole capsicum cropping systems under tunnels is almost the same. Around 36 irrigations per acre on average are

Table 1. Application of irrigations, farm yard manure and pesticide spray on selected cropping systems under tunnels.

\begin{tabular}{ccccc}
\hline Cropping Systems & \multicolumn{2}{c}{ Capsicum-Bitter-gourd } & \multicolumn{2}{c}{ Sole Capsicum } \\
\hline Frequency Distribution & Frequency & Percentage & Frequency & Percentage \\
\hline Method of Irrigation & & & & \\
Furrow & 4 & 2.67 & 7 & 4.67 \\
Basin/Flood & 146 & 97.33 & 143 & 95.33 \\
Number of Irrigations & & & & \\
Below 30 & 39 & 26.00 & 36 & 24.00 \\
Above 30 & 111 & 74.00 & 114 & 76.00 \\
Total & 100 & 150 & 100 & \\
Overall Average & \multicolumn{2}{c}{$35.67(6.39)$} & \multicolumn{2}{c}{35.78 (6.98) }
\end{tabular}

Note: Values in Parentheses of overall average shows the standard deviation. Source: Author's own calculation from survey data, collected in year 2014. 
required in bitter gourd-capsicum and sole capsicum cropping systems. The bitter gourd-capsicum farmers applied 26 and 74 percent of irrigations per acre below 30 and above 30, respectively. In a sole capsicum cropping system, around 24 percent and 76 percent of the farms have below 30 and above 30 numbers of irrigations per acre, respectively. Hence, these cropping systems under tunnels are highly water intensive. Delayed application of irrigations may result in destruction and low productivity of crops. The reduction in poverty has also been recorded relative to rain-fed farming in those areas in Asia where distribution of water has been just a 20 percent [29]. Therefore, timely and equitable distribution of irrigation water is beneficial for development of multiple cropping farms under tunnels.

The empirical analysis of both of the cropping systems selected for the water efficiency analysis in this study display dissimilar and inefficient performance in utilization of water resources on its optimal scale. Thus, it has become essential to improve the working of less performing systems for adding to enhance the features of efficient systems.

The results obtained from water efficiency analysis of multiple cropping systems under the tunnels (Figure 1) reported that every cropping system has its own technical features and irrigation requirements. The average water efficiency of multiple cropping systems is around 0.49 . The result from the DEA variable returns to the scale model demonstrates the wide range of efficiency scores among the farms of multiple cropping systems with variation as wide as $20 \%$ to $100 \%$.

The results show that if there is a reduction in inputs of irrigation systems by around $51 \%$, the same level of output can be obtained in case of multiple cropping systems. The irrigation system, which is linked with multiple cropping systems, should manage in a way to fall on efficient scale. Another considerable point is that wherever an average depth of water (inches) is increased in irrigation systems, the efficiency turns out be quite low. It reveals that the farm managers

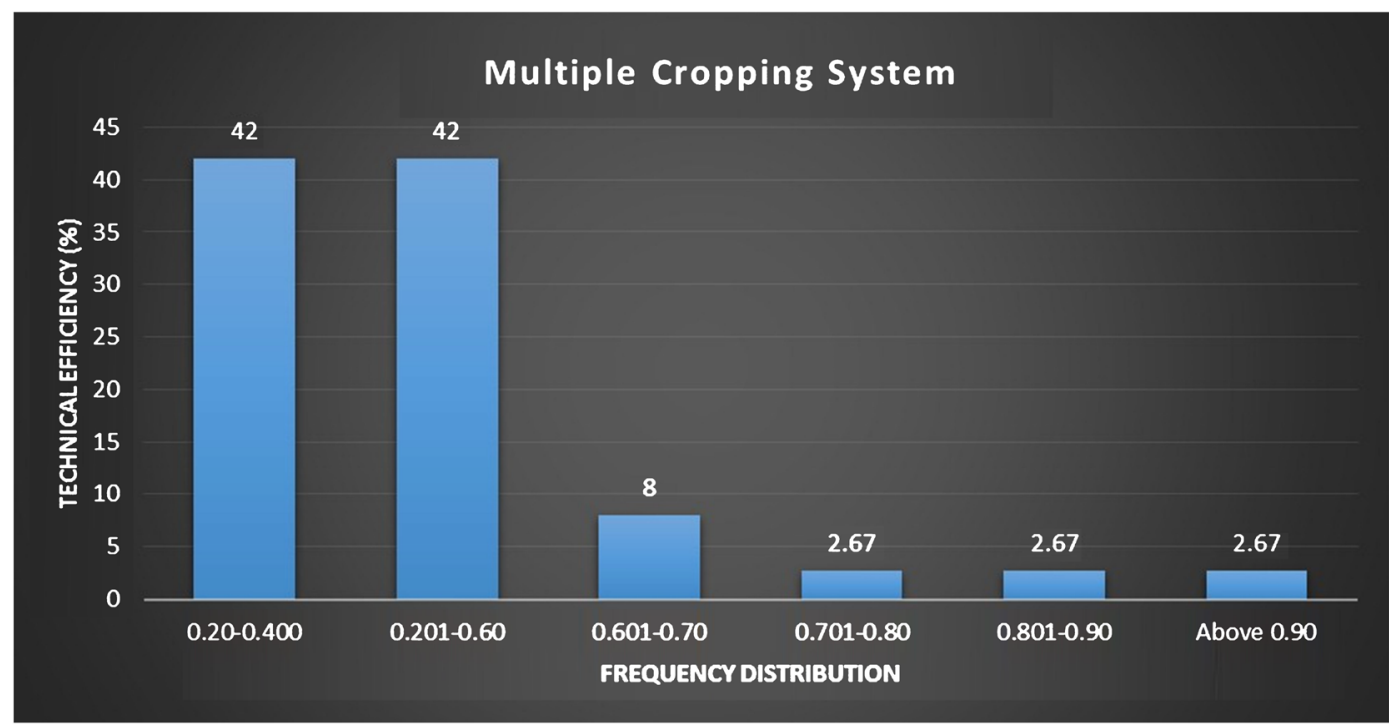

Figure 1. Water efficiency analysis of multiple cropping system. 
lacking information about the water intake requirement for multiple crops grown at the same space and time.

Different crops have varying needs of irrigation and differing water requirements in various growth stages of the crops [30]. Meter reading might be used in farms dependent upon water, supplied through irrigation. It is one of the better ways to find out the amount of water being used by each crop [31].

Farmers of the study area under this cropping system, instead of the balanced application of water, had the tendency to supply more water to multiple crops for attaining the highest level of farm output. This trend leads to inefficient utilization of one of the scarcest resources i.e. water. The current circumstances require change the mind-set of the farmers that appropriate and balanced application of farm resources always manifold the farm advantages as well as secure the farm resources.

The average efficiency of sole capsicum cropping system is around 0.83 . The results imply that, if technical inefficiency ceases to exist, around $17 \%$ increase in production can be observed while using the current technology. The DEA results show the wide range of efficiency scores among the sole cropping system farms with variation as wide as $60 \%$ to $100 \%$ under the Variable Returns to Scale (VRS). However, high level of inefficiency is observed in the use of water resources as compared to other inputs. Moreover, the inefficient water use exists in the sole (capsicum) cropping farms under the tunnels in the selected study area.

The water efficiency analysis (Figure 2) of both the selected cropping systems reported a high degree of water inefficiency in Pakistan. The multiple cropping systems have more serious issues while comparing to sole cropping system, regarding the inefficient utilization of water. Due to multiple crops, grown on same space and time, it might be in mind of the farmers that by supplying more water resulted in higher farm production. The studies show that over-irrigation

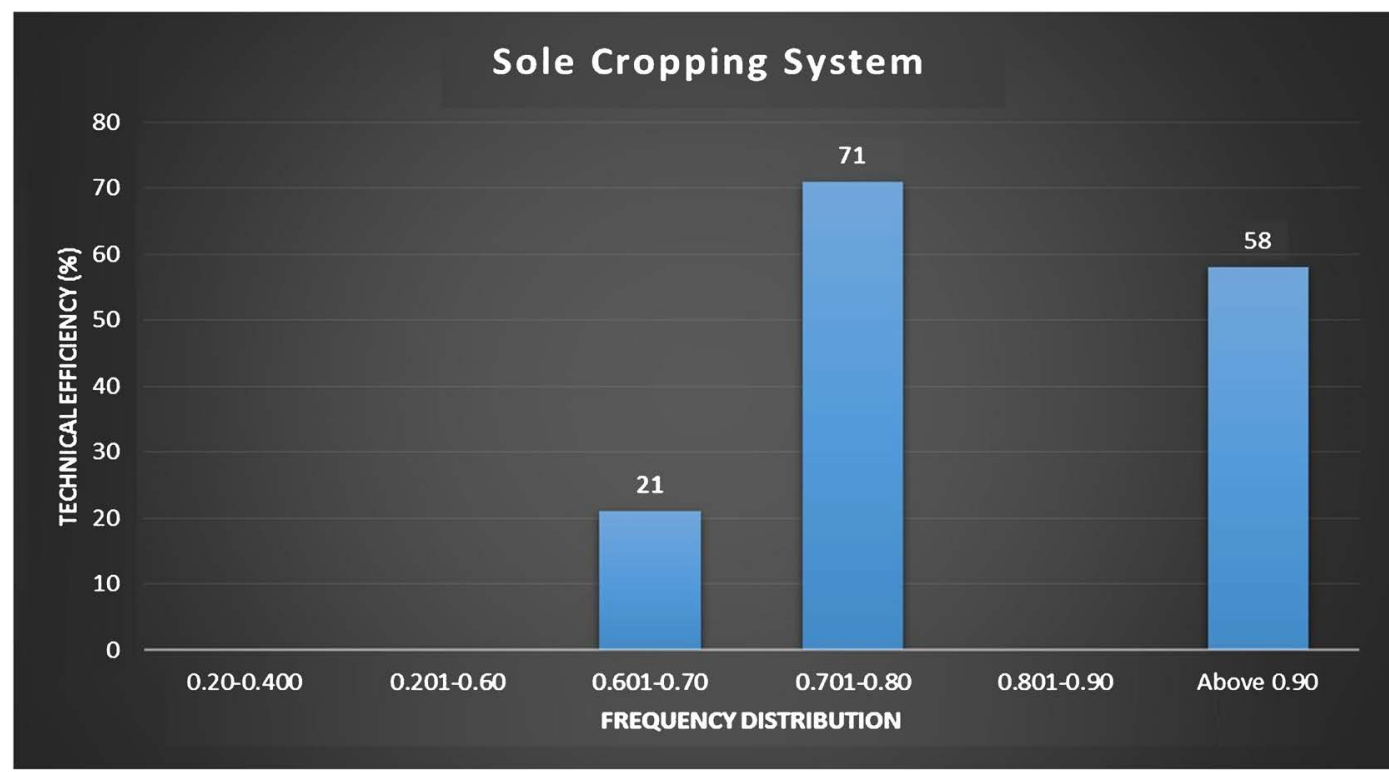

Figure 2. Water efficiency analysis of sole cropping system. 
does not contribute to adding up to any yield per unit of land. It is, therefore, needed that the farmers should be trained and educated (knowledge about farming techniques and cropping systems) regarding the water requirement as per the selected cropping system. The excess and inefficient use of one of the most important resources, on one hand, has pressurized the environment and deteriorated the table while on the other hand; it raised the farming cost and declined the profitability. Through the sound farming and current technological knowledge, especially in case of advanced farming, the water use can be made efficient.

\section{Second Stage of Water Efficiency Analysis}

The result of the study acquired from Tobit regression analysis is reported in Table 2. The results are reported that number of irrigation has a positive and significant effect on the technical efficiency of water in both sole and multiple cropping systems. As the number of irrigation increased, it shows positive impact on both systems in hand. It is an imperative input factor, if applied observantly and on time, gives rise to the efficiency of other inputs, such as fertilizers. According to Abedullah et al. 2006 [32] and Alam, 2012 [33], the number of irrigation enhance the farm output by refining the performance of other farm inputs. In case of multiple cropping systems, as number of labor increased, it positively and significantly affects the water efficiency under the multiple cropping systems. According to Amaza and Olayemi, 2002 [34] appropriate employment of farm labor is an accommodating factor in progressing the farm production. But in case of sole cropping system, the number of labor has negative impact on water efficiency. The reason behind the positive and negative signs in multiple and sole cropping systems, respectively, is that the multiple cropping systems required more labor due to multifaceted management of multiple crops under this system. Hence, as working hands increased, it positively affects the multiple cropping systems. The opposite holds in case of sole cropping system, the labor, no doubt, as important as multiple cropping systems, but the excessive use of this input has negative rather insignificant impact on the sole cropping system. Therefore, instead of excessive application of labor input, it is important to hire

Table 2. Factors affecting the water efficiency of selected cropping systems.

\begin{tabular}{cccccccccc}
\hline & \multicolumn{3}{c}{ Multiple Cropping System } & \multicolumn{3}{c}{ Sole Cropping System } \\
\cline { 2 - 9 } Parameters & Coef & Std.Er & t-value & Prob & Coef & Std.Er & t-value & Prob \\
\hline No. Irrigation & 0.0032 & 0.0016 & $1.93^{\star * *}$ & 0.056 & 0.0042 & 0.0019 & $2.22^{\star *}$ & 0.0028 \\
No. Labor & 0.0157 & 0.0059 & $2.63^{\star *}$ & 0.009 & -0.0087 & 0.0121 & -0.73 & 0.470 \\
Education & 0.0081 & 0.0032 & $2.52^{* *}$ & 0.013 & 0.0265 & 0.0053 & $4.95^{*}$ & 0.000 \\
Experience & 0.0010 & 0.0014 & 0.71 & 0.477 & 0.0010 & 0.0016 & 0.62 & 0.537 \\
Soil Type & 0.0962 & 0.0222 & $4.34^{*}$ & 0.000 & 0.095 & 0.0278 & $3.43^{*}$ & 0.001 \\
\hline
\end{tabular}

Note: $10 \%$ Significance ${ }^{\star}, 5 \%$ Significance ${ }^{\star *}$ and $1 \%$ Significance ${ }^{\star * \star}$. 
appropriate level of labor in both of the cropping systems.

The results of the study revealed that the farmers' education has a positive influence on water efficiency of both multiple and sole cropping systems. Asadullah and Rahman, 2005 [35] studied that education has a positive impact on farmer's farming skills. Educated farmers are mostly quick to respond about the adoption of latest farm technologies available in the market [36]. According to Reimers and Klasen, 2002 [37] farmer's basic education increase the returns on farm efficiency and productivity. The educated farmers are most of the time well aware about the consequences of appropriate application of inputs, such as seed varieties and advanced inputs.

The results of Tobit analysis also reported that the influence of farmers' experience on water efficiency. It revealed positive, but insignificant impact on water efficiency under the sole and capsicum cropping systems. According to the author's observations, the introduction of tunnel farming system in Pakistan is quite new. The farmers of the study area, on average, had three to five years of experience of sole and multiple cropping systems under the tunnels. Thus, this is quite the reason that the farmers are found less experienced under these systems, due to which; they don't have influential effects on water efficiency under both the cropping systems.

The soil type variable in this study used as a dummy variable in the study area as the farms were usually situated on two types of soil: loam or sandy loam. The type of sandy loam used as a base category. The results of the study report positive and significant association between water efficiency and soil type. It was demonstrated that the farms, which had loam soil, were found more water efficient than sandy loam farms. According to Belel and Dahab, 1997 [38] and Hunt, 2013 [39] soil type is one of the fundamental factors in determining the farm productivity and efficiency. It has a direct effect on the land preparation activities and application of fertilizers on farm, such as texture of soil and its properties is helpful in transmission of soil nutrient and water. In addition, the farmers who were aware about the type of soil of their farms and about the water requirement, they were also found more able to irrigate their crops efficiently. Therefore, their approach leads to the highest level of water efficiency and farm output.

There exists a connection between wealth and irrigation because irrigation enhances agricultural output. Water, being a scarce resource, stand out as one of the indicators to point out towards socio economic standing. At present the water usage in terms of irrigation, is inefficient leading to high rate of water loss, especially in case of multiple cropping system which can be attributed to absence of maintenance of irrigation system, lack of knowledge regarding applicable irrigation practices under multiple cropping systems. In the light of these facts, irrigation practices ought to be improved and the efficient techniques need to be promoted not only for agricultural sector rather for all water using sectors of the economy. 


\section{Conclusions}

Around the world, Pakistan is one of the countries that would be in line to face the problem of sever water scarcity in upcoming years. Pakistan's intimidated expedition from water stressed to water scarce country is alarming. Over the years several reports of national and international organization reported the sever water scarcity state in Pakistan. The major reasons of water scarcity are inefficient supply of water through canals, over utilization of groundwater, insufficient water storage capability and pollution, due to which quality of water is deteriorated in Pakistan.

Above all, lack of applicability of the concept of "Beyond crop per drop" hence, continuous cultivation of crops that required higher percentage of water e.g. sugarcane is also one of the reasons of water scarcity in Pakistan. It is need of the hour that Pakistan should espouse the idea of virtual water trade on one hand and multiple cropping systems on other hand.

In Pakistan, sustainable methods regarding farm sector should be adopted. Why? Because Pakistan is one of the countries that has the largest withdrawal of water for farm sector [40]. Hence, the efficient utilization scarce inputs such as water are required. The continuous rising growth in population of Pakistan resulted in competing claims on water use and its distribution. On the other hand, due to rapid climatic changes and environmental hazards, it is essential to optimize and symmetries the scarce natural resources in one of the most efficient and manners. This study has done the comparative efficiency analysis of sole and multiple cropping systems. The results to the study suggested that adaptation of smart agriculture systems such as multiple cropping system is one of the ways towards efficiency utilization of water in Pakistan.

In the study area, most of the water requirement for crops is fulfilled by underground water while some of water is supplied through irrigation. This kind of high dependence on ground water has pressurized the environment and is causing it to deteriorate making the water tables fall at alarmingly low levels in Pakistan. The readily available water at low and subsidized costs, may have lowered the efficiency of using water.

The annual rainfall in Pakistan showed a significant decline all over the country then, consequently reducing the rivers flows. Thereafter, an extremely serious water crisis emerged in Pakistan threatening its irrigated agriculture and domestic water supplies. In this regard efficient application of water on farm sector is very important because farm sector is one of the major consumers of available water in Pakistan (around 97 percent of water is used for agriculture). Keeping in view the water availability to the both selected cropping systems (Capsicum-bitter gourd and sole capsicum cropping systems) the water efficiency is far below than the achievable levels in both cropping systems. It is most probably due to conveyance and application losses, improper irrigation scheduling and lack of awareness of regarding irrigation management.

The result of the study clearly reported the high level of inefficiencies espe- 
cially in case of multiple cropping system (51\%), which is generally considered to be more water efficient if the irrigation scheduling and application of irrigation is well managed. It therefore becomes very important to develop an action plan in order to conserve and utilize the dwindling water resources. Existing irrigation practices need to be changed and new roles and new accountabilities must be allowed to emerge in water sector of Pakistan. For instance, in most of the areas, the actual water application varies considerably from the required irrigation demand. Consequently, there is high potential for water savings by improving irrigation efficiency. New irrigation technologies will help this process, as will better water allocation practices and regulations, and better dialogue about the relationship between water for food and water for the environment.

- At farm level, farmers are needed to upgrade their farm knowledge and employ the most efficient and productive farm and irrigation practices regarding water application under multiple and sole cropping systems.

- On institutional level, it is required to introduce and transmit the most efficient irrigation techniques at farm level in order to maximize the use of water input in farm sector of Pakistan.

- New cropping patterns (especially water saving cropping systems, i.e. low delta crops) along with efficient irrigation systems are needed to be introduced for overcoming the issue of water scarcity in the country.

\section{Author Contributions}

The main idea, data collection, methodology, empirical analysis and investigations are done by Dr. Hina Fatima. Overview, technical input and supervision on every step of this research are provided by Professor Dr. Lal K. Almas (Corresponding Author). The introduction, literature review, references and graphical analysis are done by Sehrish Haroon.

\section{Acknowledgements}

The research in this manuscript has partially been supported by the Ogallala Aquifer Program, a consortium of the USDA Agricultural Research Service, Kansas State University, Texas A \& M AgriLife Research, Texas A \& M AgriLife Extension Service, Texas Tech University, and West Texas A \& M University.

\section{Conflicts of Interest}

The authors declare no conflicts of interest regarding the publication of this paper.

\section{References}

[1] Thiam, A., Bravo-Ureta, B. and Rivas, T. (2001) Technical Efficiency in Developing Country Agriculture: A Meta-Analysis. Agricultural Economics, 25, 235-243. https://doi.org/10.1111/j.1574-0862.2001.tb00204.x

[2] Pakistan Government of (Various Issues). Economic Survey of Pakistan. Ministry of 
Finance Islamabad, Islamabad.

[3] Wagan, H.F. and Khoso, S. (2013) Water Shortage Its Causes, Impacts and Remedial Measures. 6th International Civil Engineering Congress, Karachi, 28 December 2013, 7 p.

[4] Ashraf, M. and Sheikh, A.A. (2017) Sustainable Groundwater Management in Balochistan. Pakistan Council of Research in Water Resources (PCRWR), Islamabad, 34.

[5] Ashraf, M. and ul Hassan, F. (2018) Pakistan's Deserts: Land and Water Resources Development. Higher Education Commission, Islamabad, 38.

[6] Mohtadullah, K., Rehman, A. and Munir, M.C. (1991) Water Use and Misuse. NCS, Islamabad.

[7] Ashraf, M., Hassan, F.U. and Khan, M.A. (1999) Water Conservation and Its Optimum Utilization in Barani Areas. Journal of Science Technology and Development, 18, 28-32.

[8] Hussain, R. and Qureshi, M.A. (2019) Water Security Issues of Agriculture in Pakistan. Pakistan Academy of Sciences, Islamabad.

[9] Ashraf, M. (2015) Promising Land and Water Management Practices: ICARDA.

[10] Federal Bureau of Statistics (2001) Statistics Division, Government of Pakistan, Pakistan Statistical Yearbook 2001.

[11] Banerji, J.V. and Meenakshi, G.K. (2006) Groundwater Irrigation in North India: Institutions and Markets. SANDEE Working Paper No. 19-06.

[12] Khan, S.R. (1997) Does Climate Change Matter in Pakistan? SDPI News and Research Bulletin, 3, 8-11.

[13] Kahlown, M.A., Shafique, S.M. and Iqbal, M. (1998) Improved Irrigation Methods for Efficient Use of Irrigation Water under Different Water-Table Depths. Mona Reclamation Experimental Project, WAPDA, Pub. No. 231.

[14] Watto, M. (2013) Measuring Groundwater Irrigation Efficiency in Pakistan: A DEA Approach Using the Sub-Vector and Slack-Based Models. 57th AARES Annual Conference at the Sydney Convention and Exhibition Centre in Darling Harbour, Sydney, 5-8 February 2013, 35 p.

[15] Jalota, S.K., Sood, A., Chahal, G.B.S. and Choudhury, B.U. (2006) Crop Water Productivity of Cotton (Gossypium hirsutum L.) Wheat (Triticum aestivum L.) System as Influenced by Deficit Irrigation, Soil Texture and Precipitation. Agricultural Water Management, 84, 137-146. https://doi.org/10.1016/j.agwat.2006.02.003

[16] Guerra, L.C., Bhuiyan, S.I., Tuong, T.P. and Barker, R. (1998) Producing More Rice with Less Water from Irrigated Systems. SWIM Paper No. 5, International Water Management Institute, Colombo.

[17] Shideed, K.H., Oweis, T., Gabr, M. and Osman, M. (2005) Assessing On-Farm Water Use Efficiency: A New Approach. 86 p.

[18] Aziz, D., Masood, A. and Hashmi, Z. (2018) Turning the Tide. The News International. https://www.thenews.com.pk/print/328174-turning-the-tide

[19] Pakistan Government of (2018) Pakistan Council of Research in Water Resources (PCRWR). Ministry of Science and Technology, Islamabad.

[20] Shukla, V. (2018) Pakistan's Alarming Water Crisis: Country to Run Out of Clean Water by 2025. Politics.

https://www.valuewalk.com/2018/05/pakistan-water-crisis-clean-water-2025

[21] Farrell, M.J. (1957) The Measurement of Productive Efficiency. Journal of the Royal 
Statistical Society: Series B (Statistical Methodology), 120, 253-290. https://doi.org/10.2307/2343100

[22] Charnes, A., Cooper, W.W. and Rhodes, E. (1978) Measuring the Efficiency of Decision Making Units. European Journal of Operational Research, 2, 429-444. https://doi.org/10.1016/0377-2217(78)90138-8

[23] Banker, R.D., Charnes, A. and Cooper, W.W. (1984) Some Models for the Estimation of Technical and Scale Inefficiencies in Data Envelopment Analysis. Management Science, 30, 1078-1092. https://doi.org/10.1287/mnsc.30.9.1078

[24] Wooldridge, J.M. (2002) Econometric Analysis of Cross Section and Panel Data. MIT Press, Cambridge.

[25] Coelli, T.R., Pardse, D.S. and Battese, G.E. (1998) An Introduction to Efficiency and Productivity Analysis. Kluwer Academic, Boston. https://doi.org/10.1007/978-1-4615-5493-6

[26] Dhungana, R.B., Nuthall, V.G., Nartea and Peatr, L.P. (2004) Measuring the Economic Inefficiency of Nepalese Rice Farms Using Data Envelopment Analysis. Australian Journal of Agricultural and Resource Economics, 48, 347-369. https://doi.org/10.1111/j.1467-8489.2004.00243.x

[27] Berkhout, M. (1997) Farmer's Use of Basin, Bed and Furrow and Furrow Irrigation Systems and the Possibilities for Traditional Farmers to Adopt the Bed and Furrow Irrigation Method. International Irrigation Management Institute, Report No. R-33.

[28] Anshtuz, J.D. and Chavez, H.B. (1985) Drip Irrigation at Superior Farming Company. Drip/Trickle Irrigation in Action. Proceedings of the Third International Drip/ Trickle Irrigation Congress, Vol. 1, 8-12.

[29] Lipton, M. (2007) Farm Water and Rural Poverty Reduction in Developing Asia. Irrigation and Drainage, 56, 127-146. https://doi.org/10.1002/ird.302

[30] Crowell, C. (1986) TVA Partnerships AFOR Ground-Water Protection. Groundwater, 24, 692-693. https://doi.org/10.1111/j.1745-6584.1986.tb01685.x

[31] Almas, L.K., Colette, W.A. and Warminski, P.L. (2007) Reducing Irrigation Water Demand with Cotton Production in West Texas. Southern Agricultural Economics Association Annual Meeting, Mobile, 4-7 February 2007, 18 p. https://ageconsearch.umn.edu/record/34848

[32] Abedullah, B.K. and Ahmad, B. (2006) Technical Efficiency and Its Determinants in Potato Production Evidence from Punjab Pakistan, Lahore. Journal of Economics, 11, 1-22. https://doi.org/10.35536/lje.2006.v11.i2.a1

[33] Alam, A., Hajime, K., Ichizen, M., Akira, I., Esham, M. and Faridullah (2012) Technical Efficiency and Its Determinants in Potato Production: Evidence from Northern Areas in Gilgit-Baltistan of Pakistan. International Journal of Research in Management, Economics and Commerce, 2, 1-17.

[34] Amaza, P.S. and Olayemi, J.K. (2002) Analysis of Technical Inefficiency in Food Crop Production in Gombe State, Nigeria. Applied Economics Letters, 9, 51-54. https://doi.org/10.1080/13504850110048523

[35] Asadullah, M.N. and Rahman, S. (2005) Farm Productivity and Efficiency in Rural Bangladesh: The Role of Education Revisited. Applied Economics, 41, 17-33.

[36] Fatima, H. and Azeem, K. (2015) Influence of Wheat Varieties on Technical Efficiency and Production of Wheat Crop in Pakistan (In Selected Area of Punjab). Sarhad Journal of Agriculture, 31, 114-122. https://doi.org/10.17582/journal.sja/2015/31.2.114.122

[37] Reimers, M. and Klasen, S. (2012) Revisiting the Role of Education for Agricultural 
Productivity. American Journal of Agricultural Economics, 95, 131-152. https://doi.org/10.1093/ajae/aas118

[38] Belel, M.M. and Dahab, H.M. (1997) Effect of Soil Conditions on a Two-Wheel Drive Tractor Performance Using Three Types of Tillage Implements. The Journal of Agricultural Science, 5, 1-20.

[39] Hunt, D. (2013) Farm Power and Machinery Management. 10th Edition, Waveland Press, Dublin.

[40] Scheierling, S.M. and Treguer, D.O. (2018) Beyond Crop per Drop: Assessing Agricultural Water Productivity and Efficiency in a Maturing Water Economy. The World Bank, Washington DC. https://doi.org/10.1596/978-1-4648-1298-9 